\title{
L-Lactate dehydrogenase $B$ may be a predictive marker for sensitivity to anti-EGFR monoclonal antibodies in colorectal cancer cell lines
}

\author{
AYUMU NAGAMINE ${ }^{1,2}$, TAKUYA ARAKI $^{1,2}$, DAISUKE NAGANO ${ }^{1}$, \\ MITSUE MIYAZAKI $^{3}$ and KOUJIROU YAMAMOTO ${ }^{1,2}$ \\ ${ }^{1}$ Department of Clinical Pharmacology and Therapeutics, Gunma University Graduate School of Medicine; \\ ${ }^{2}$ Department of Pharmacy, Gunma University Hospital; ${ }^{3}$ Division of Endocrinology Metabolism and \\ Signal Research, Gunma University Initiative for Advanced Research and Institute for Molecular \\ and Cellular Regulation, Maebashi, Gunma 371-8511, Japan
}

Received October 15, 2018; Accepted January 31, 2019

DOI: $10.3892 / \mathrm{ol} .2019 .10075$

\begin{abstract}
Recently, proteins derived from cancer cells have been widely investigated as biomarkers for predicting the efficacy of chemotherapy. In this study, to identify a sensitive biomarker for the efficacy of anti-epidermal growth factor receptor monoclonal antibodies (anti-EGFR mAbs), proteins derived from 6 colorectal cancer (CRC) cell lines with different sensitivities to cetuximab, an anti-EGFR mAb, were analyzed. Cytoplasmic and membrane proteins extracted from each CRC cell line were digested using trypsin and analyzed comprehensively using mass spectrometry. As a result, 148 and 146 peaks from cytoplasmic proteins and 363 and 267 peaks from membrane proteins were extracted as specific peaks for cetuximab-resistant and -sensitive CRC cell lines, respectively. By analyzing the proteins identified from the peptide peaks, cytoplasmic L-lactate dehydrogenase B (LDHB) was detected as a marker of cetuximab sensitivity, and it was confirmed that LDHB expression was increased in cetuximab-resistant CRC cell lines. Furthermore, LDHB expression levels were significantly upregulated with the acquisition of resistance to cetuximab in cetuximab-sensitive CRC cell lines. In conclusion, LDHB was identified as an important factor affecting cetuximab sensitivity using comprehensive proteome analysis for the first time.
\end{abstract}

Correspondence to: Dr Takuya Araki, Department of Clinical Pharmacology and Therapeutics, Gunma University Graduate School of Medicine, 3-39-22 Showa-machi, Maebashi, Gunma 371-8511, Japan

E-mail: tkyaraki@gunma-u.ac.jp

Key words: L-lactate dehydrogenase B, anti-epidermal growth factor receptor monoclonal antibodies, colorectal cancer, effect predictor, proteome

\section{Introduction}

Various factors such as genetic variations and changes in mRNA expression patterns are known to influence drug efficacy, and such factors have been studied extensively. However, drug responses are affected by changes in the conformation, localization, and expression of numerous proteins, which are regulated by mutations and mRNA expression levels. In 2014 , Zhang et al reported that only $32 \%$ of the genes showed statistically significant positive mRNA-protein correlation in 86 CRC samples (1). Therefore, proteomics analysis-the direct evaluation of the expression levels and modifications of proteins-has been focused on recently as a powerful exploration method for identifying predictive biomarkers for the efficacy of chemotherapeutic drugs.

The expression levels of some serum proteins have been reported to be useful indicators of sensitivity to chemotherapy for cancer, and Li et al reported that variation in serum LDH level was useful as a predictive biomarker of efficacy of bevacizumab in non-small cell lung cancer (NSCLC) patients (2). Furthermore, proteomic studies analyzing several serum proteins using matrix-assisted laser desorption/ionization mass spectrometry (VeriStrat; Biodesix, Boulder, CO), classified NSCLC patients treated with erlotinib, an epidermal growth factor receptor (EGFR) tyrosine kinase inhibitor, into two groups with good or poor prognosis (3-10). However, serum proteins derived from tumor tissue and circulating in blood stably represent only a small fraction of total protein derived from a tumor. Thus, to find more suitable predictive biomarkers for sensitivity to anticancer drugs, the analysis should include not only proteins released into blood but all proteins derived from a tumor.

In 2015, Sun et al (11) reported that a high level of L-lactate dehydrogenase B (LDHB) expression in tumor tissue was associated with poor overall survival in oral cancer patients treated with paclitaxel, and Ferrer et al (12) also reported that $17 \mathrm{kDa}$ membrane-associated protein expression in tumor tissue could predict sensitivity to platinum-based therapy, EGFR inhibitors, and the proteasome inhibitor bortezomib in 
lung adenocarcinoma in 2018. In a meta-analysis of clinical studies, Li et al (13) showed that aldehyde dehydrogenase 1 could be a predictor of response to neoadjuvant chemotherapy in breast cancer. Furthermore, in recent years, proteins in tumor cells have been comprehensively analyzed. Yu et al (14) identified some predictive marker proteins for sensitivity to platinum-containing drugs in patients with ovarian cancer. Moreover, Chauvin et al (15) detected predictive marker proteins for the efficacy of 5-fluorouracil (5-FU) in patients with locally advanced rectal cancer. As mentioned above, the usefulness of proteome analysis of tumor tissues to develop predictive markers for the efficacy of certain small molecule drugs has been demonstrated. On the other hand, although L-lactate dehydrogenase A (LDHA) expression levels in tumors have been reported to correlate with cetuximab sensitivity in patients with Ewing's sarcoma (16) and gankyrin has been reported to contribute to resistance to chemotherapy containing bevacizumab in CRC (17), comprehensive proteome analysis to identify predictive biomarkers for the efficacy of antibody drugs has not been conducted.

Anti-EGFR monoclonal antibodies (anti-EGFR mAbs), including cetuximab and panitumumab, are key drugs in the treatment of colorectal cancer (CRC) and are highly effective for some CRC patients. On the other hand, anti-EGFR mAbs are very expensive, and are also known to cause serious adverse effects such as an infusion reaction or skin rash. Therefore, these drugs should be used only for patients in which an effective response is expected. Many clinical trials have concluded that variations in the KRAS gene are a crucial factor affecting the clinical efficacy of anti-EGFR mAbs. Anti-EGFR mAbs have been recommended to be used for wild-type KRAS CRC patients, approximately $60 \%$ of all CRC patients. However, more than $50 \%$ of patients with wild-type KRAS tumors do not receive a therapeutic benefit from anti-EGFR mAbs (18-22). Even when variations of NRAS, BRAF, and PIK3CA mutations or EGFR overexpression are taken into account, the primary cause of resistance to anti-EGFR $\mathrm{mAbs}$ in more than half of wild-type $K R A S \mathrm{CRC}$ patients with poor drug responses remains unknown (20,23-28). As mentioned above, although genome research is widely performed and has many advantages such as the ease of the procedure, it has become clear that fluctuation in protein expression, which directly affects drug efficacy, cannot be explained with genome information alone. Thus, factors affecting drug efficacy other than genetic factors need to be studied through a comprehensive analysis, such as a proteomic approach.

In this study, we focused on time-of-flight (TOF) mass spectrometry (MS) which can be used for non-target protein analysis and comprehensive protein analysis, and performed comprehensive analysis of proteins derived from CRC cell lines without genetic mutations affecting sensitivity to anti-EGFR mAbs, such as KRAS, NRAS, BRAF, and PIK3CA mutations, and PTEN overexpression. Finally, we explored some tumor-specific proteins that were correlated with sensitivity to anti-EGFR mAbs.

\section{Materials and methods}

Materials. CACO2, C10, HT55, and C99 cell lines were purchased from the European Collection of Cell Cultures
(Salisbury, UK). The COLO320DM cell line was purchased from the Japanese Collection of Research Bioresources Cell Bank (Osaka, Japan). The SW48 cell line was obtained from the American Type Culture Collection (Manassas, VA, USA). These cell lines were classified into three groups according to cetuximab sensitivity: C99 and SW48 in the cetuximab-sensitive group (Cmab-S), C10 and HT55 in the cetuximab-partial resistance group (Cmab-PR), and CACO2 and COLO320DM in the cetuximab-resistance group (Cmab-R). Reagents for culture [culture medium, fetal bovine serum (FBS), and supplements] and sample preparation (dithiothreitol, iodoacetamide, and trypsin) were purchased from Wako Pure Chemical Industries (Osaka, Japan). All other reagents were obtained from commercial sources, and those used to analyze peptides were graded for high-performance liquid chromatography, liquid chromatography-tandem mass spectrometry (LC-MS/MS), or analytical use. Standard peptides used for MS analysis were synthesized by Eurofins Genomics Japan (Tokyo, Japan).

Cell culture and sample preparation. Six CRC cell lines with different sensitivities to cetuximab were used in this study (Table I) (29). CACO2, COLO320DM, C10, HT55, and C99 cells were cultured in a humidified incubator at $37^{\circ} \mathrm{C}$ in the presence of $5 \% \mathrm{CO}_{2}$, while SW48 cells were cultured in a $37^{\circ} \mathrm{C}$ incubator with no supplemental $\mathrm{CO}_{2}$. Cetuximab-acquired resistance cell lines (SW48R and C99R) were generated upon continuous exposure of SW48 and C99 cell lines to cetuximab according to the method of Troiani et al (30). Briefly, for a period of 8 months, SW48 and C99 cells were continuously exposed to cetuximab to increase the inhibition of $50 \%$ of cancer cell growth $\left(\mathrm{IC}_{50}\right)$, and the final concentration was $12.8 \mu \mathrm{g} / \mathrm{ml}$. Cytoplasmic and membrane proteins were extracted from $80 \%$ confluent cell lines using a Minute Plasma Membrane Protein Isolation kit (Invent Biotechnologies, Inc., Plymouth, MN, USA), and the concentrations of the extracted proteins were measured using a DC ${ }^{\mathrm{TM}}$ Protein assay kit (Bio-Rad Laboratories, Inc., Hercules, CA, USA). Cytoplasmic and membrane protein extracts were diluted to 2.0 and $1.0 \mathrm{mg} / \mathrm{ml}$, respectively, and assayed immediately or stored at $-80^{\circ} \mathrm{C}$ until assay.

Mass spectrometry analysis. As a pretreatment for cytoplasmic and membrane protein samples, protein samples (45 $\mu \mathrm{l})$ were mixed with $1 \mathrm{mg} / \mathrm{ml}$ infliximab $(5 \mu \mathrm{l})$ and an internal standard (ISTD), and incubated at $37^{\circ} \mathrm{C}$ for $30 \mathrm{~min}$ with urea $(41 \mathrm{mg}$ ) and $40 \mathrm{mg} / \mathrm{ml}$ dithiothreitol $(7.7 \mu \mathrm{l})$ in $8 \mathrm{~mol} / \mathrm{l} \mathrm{urea} / 0.5 \mathrm{~mol} / \mathrm{l}$ Tris $\mathrm{HCl}(\mathrm{pH} 8.5)$ to reduce disulfide bonds. Reduced samples were alkylated by reaction with $40 \mathrm{mg} / \mathrm{ml}$ iodoacetamide in $8 \mathrm{~mol} / \mathrm{l}$ urea/0.5 mol/1 Tris- $\mathrm{HCl}(19.2 \mu \mathrm{l}$; pH 8.5) for $30 \mathrm{~min}$ at $37^{\circ} \mathrm{C}$. Subsequently, to digest the proteins, cytoplasmic and membrane protein samples (300 $\mu \mathrm{l}$ each, diluted 4-fold with Milli-Q water) were trypsinized by adding trypsin solution (42 and $22 \mu \mathrm{l}$, respectively; $100 \mu \mathrm{g} / \mathrm{ml}$ in $20 \mathrm{mmol} / 1$ acetic acid) and incubating at $37^{\circ} \mathrm{C}$ for $12 \mathrm{~h}$. Surfactants in the membrane protein samples were removed with Detergent OUT ${ }^{\mathrm{TM}}$ (Takara Bio, Inc., Shiga, Japan), and trypsinized samples were desalted using a MonoSpin C18 column (GL Sciences, Inc., Tokyo, Japan).

Peptide fragments analysis was performed using liquid chromatography-time-of-flight mass spectrometry (LC-TOF 
Table I. Cetuximab sensitivities and culture of six CRC cell lines.

\begin{tabular}{llcl}
\hline Cell line & Cetuximab sensitivity & $\begin{array}{c}\text { Growth inhibition } \\
\text { relative to control }(\%)\end{array}$ & \multicolumn{1}{c}{ Culture medium } \\
\hline CACO2 & Resistant & 0 & EMEM + 1\% NEAA + 10\% FBS \\
COLO320DM & Resistant & 0 & RPMI1640 + 10\% FBS \\
C10 & Partially resistant & 5.9 & IMDM + 10\% FBS \\
HT55 & Partially resistant & 21.3 & EMEM + 1\% NEAA + 20\% FBS \\
SW48 & Sensitive & 69.1 & L15 + 10\% FBS \\
C99 & Sensitive & 96.8 & IMDM + 10\% FBS \\
\hline
\end{tabular}

CRC, colorectal cancer; NEAA, non-essential amino acids; FBS, fetal bovine serum.

MS) consisting of an ACQUITY UPLC (Waters, Milford, MA, USA) for LC and LCT Premier XE (Waters) for TOF MS. The LC conditions were as follows: Column, ACQUITY UPLC BEH C18 column ( $2.1 \mathrm{~mm}$ x $100 \mathrm{~mm}, 1.7 \mu \mathrm{m}$ ) (Waters); column temperature, $40^{\circ} \mathrm{C}$; mobile phase, $0.1 \%$ formic acid in Milli-Q water (A) and $0.1 \%$ formic acid in acetonitrile (B); flow rate, $0.3 \mathrm{ml} / \mathrm{min}$; and gradient program, 5 to $95 \% \mathrm{~B}$ in $55 \mathrm{~min}$ and 95 to $5 \% \mathrm{~B}$ in $3 \mathrm{~min}$. MS analysis was performed using an electrospray ionization (ESI) source in positive ionization mode (W mode). Survey scans were acquired in the range 100 to $2000 \mathrm{~m} / \mathrm{z}$. Instrument settings were as follows: Capillary voltage, $3000 \mathrm{~V}$; sample cone voltage, $50 \mathrm{~V}$; desolvation temperature, $350^{\circ} \mathrm{C}$; source temperature, $120^{\circ} \mathrm{C}$; cone gas flow, $60 \mathrm{l} / \mathrm{h}$; desolvation gas flow, $700 \mathrm{l} / \mathrm{h}$; and aperture 1 voltage, $15 \mathrm{~V}$.

Tandem quadrupole MS was used to analyze specific peptide fragments. LC was performed with an ACQUITY UPLC system (Waters). An ACQUITY UPLC BEH C18 column $(2.1 \mathrm{~mm} \times 100 \mathrm{~mm}, 1.7 \mu \mathrm{m})$ (Waters) was used as the LC column. The LC conditions were as follows: Column temperature, $40^{\circ} \mathrm{C}$; mobile phase, $0.1 \%$ formic acid in Milli-Q water (A) and $0.1 \%$ formic acid in acetonitrile (B); flow rate, $0.5 \mathrm{ml} / \mathrm{min}$; and gradient program, 5 to $35 \% \mathrm{~B}$ in $6 \mathrm{~min}, 35$ to 95\% B in $1 \mathrm{~min}$, and 95 to 5\% B in $1 \mathrm{~min}$. XevoTQ (Waters) with ESI turbo spray in positive ionization mode was used, and the ionization parameters were as follows: Capillary voltage, $1000 \mathrm{~V}$; desolvation temperature, $500^{\circ} \mathrm{C}$; source temperature, $150^{\circ} \mathrm{C}$; desolvation gas flow, $1000 \mathrm{l} / \mathrm{h}$; and cone gas flow, $70 \mathrm{l} / \mathrm{h}$. The transitions $\mathrm{m} / \mathrm{z} 1176.53>130.85$ for LDHB and $\mathrm{m} / \mathrm{z}$ $835.44>175.20$ for ISTD were monitored. Sample cone voltage and collision energy were 74 and $80 \mathrm{~V}$ for LDHB and 35 and $55 \mathrm{~V}$ for ISTD, respectively.

Proteomics analysis. Principal component analysis (PCA) and orthogonal projections for latent structure-discriminant analysis (OPLS-DA) using MarkerLynx XS software (Waters) were performed on all peaks obtained from Cmab-R and Cmab-S cell lines by LC-TOF MS analysis with the following parameters: Initial retention time, $0.1 \mathrm{~min}$; final retention time, $55.0 \mathrm{~min}$; peak width at $5 \%$ height, $3.00 \mathrm{~s}$; peak-to-peak baseline noise, 50.00; mass tolerance, $0.05 \mathrm{Da}$; intensity threshold, 10 counts; mass window, $0.05 \mathrm{Da}$; and retention time window, 0.10 min. In OPLS-DA, the peaks were grouped into Cmab-R and Cmab-S, and cut-off values for Pearson's correlation coefficients \pm 0.8 were used to define the peaks associated with sensitivity to cetuximab. Among the selected peaks, the peaks without isotopic peaks were excluded, and the peaks with intensities that were significantly correlated with cetuximab sensitivity in the six CRC cell lines, including Cmab-PR, were finally extracted. Thereafter, the proteins composing the extracted peaks were determined using MS fit analysis (ProteinProspector; http://prospector.ucsf.edu/prospector/mshome.htm).

Statistical analysis. Correlations between the peak intensities and growth inhibitory concentration of cetuximab, an index of cetuximab sensitivity, were evaluated based on Pearson's correlation coefficient. Differences in LDHB expression levels between groups were evaluated by One-way analysis of variance (ANOVA) and Mann-Whitney U test. The Tukey-Kramer test was used for post hoc analysis. Statistical analysis was performed using SPSS software version 24.0 (SPSS, Inc., Chicago, IL, USA). A P-value less than 0.05 was considered statistically significant.

\section{Results}

Exploration of predictive marker proteins. PCA was performed on data of the MS peaks obtained from Cmab-R and Cmab-S using LC-TOF MS. A total of 1,599 and 1,012 peaks that were specific to cytoplasmic proteins of Cmab-R and Cmab-S, respectively, and 2,370 and 3,478 peaks that were specific to membrane proteins of Cmab-R and Cmab-S, respectively, were detected. Then, we extracted 271 and 197 peaks as monoisotopic ion peaks that were specific to cytoplasmic proteins of Cmab-R and Cmab-S, respectively, and excluded other peaks as isotopic peaks or noise peaks. Similarly, 533 and 422 peaks were extracted as monoisotopic peaks that were specific to membrane proteins of Cmab-R and Cmab-S, respectively. Finally, 148 and 146 peaks from cytoplasmic proteins and 363 and 267 peaks from membrane proteins were extracted as candidate specific peaks to Cmab-R and Cmab-S, respectively, the intensities of which were significantly correlated with cetuximab sensitivity in the six CRC cell lines. Candidate proteins composed of those peaks were identified by MS fit analysis, and LDHB in the cytoplasmic fraction showed the highest MOWSE score, an indicator of the probability of protein identification (Table II). 
Table II. Candidate marker proteins for cetuximab sensitivity.

\begin{tabular}{cccllll}
\hline No. & $\begin{array}{c}\text { MOWSE } \\
\text { score }\end{array}$ & \% Coverage & \multicolumn{1}{c}{ Protein name } & Accession no. & Fraction & Marker \\
\hline 1 & 7198 & 14.4 & L-lactate dehydrogenase B chain & P07195 & Cytoplasm & Cmab-R \\
2 & 911 & 10.4 & Uncharacterized protein C18orf63 & Q68DL7 & Membrane & Cmab-S \\
3 & 573 & 7.1 & Serine/threonine-protein kinase TAO1 & Q7L7X3 & Membrane & Cmab-S \\
4 & 303 & 4 & Protein phosphatase Slingshot homolog 1 & Q8WYL5 & Membrane & Cmab-S \\
5 & 273 & 4.9 & Coiled-coil domain-containing protein 110 & Q8TBZ0 & Cytoplasm & Cmab-S \\
6 & 242 & 5.4 & Pre-mRNA-splicing factor ATP-dependent & O60231 & Membrane & Cmab-S \\
& & & RNA helicase DHX16 & & & \\
7 & 240 & 4.6 & Exocyst complex component 6B & Q9Y2D4 & Membrane & Cmab-S \\
8 & 237 & 7.9 & Zinc finger protein 771 & Q623S4 & Membrane & Cmab-R \\
9 & 224 & 13.5 & Protein LIAT1 & Membrane & Cmab-S \\
10 & 223 & 8.7 & Kelch-like protein 41 & O60662 & Membrane & Cmab-S \\
\hline
\end{tabular}

MOWSE, molecular weight search; Cmab-S, cetuximab-sensitive group; Cmab-R, cetuximab-resistance group.

Evaluation of the correlation between peak intensity of an LDHB-specific peptide and cetuximab sensitivity. From the final candidate peaks, six (m/z 720.40, 957.62, 754.38, 1011.57, 959.56, and 1176.60) were extracted as peptide peaks derived from LDHB by MS fit analysis, and an LDHB-specific peptide, SADTLWDIQK m/z 1176.60, was analyzed by LC-MS/MS (Fig. 1). As a result, the peak intensity of SADTLWDIQK was significantly higher in Cmab-R than in Cmab-S $(\mathrm{P}<0.05$, One-way ANOVA) (Fig. 2). Only C10, but not C99, was significantly higher in Cmab-PR than in Cmab-S $(\mathrm{P}<0.05$, One-way ANOVA) (Fig. 2). In addition, the data obtained by LC-MS/MS were consistent with data obtained by analysis using enzyme-linked immunosorbent assay (ELISA) (data not shown).

Relationship between acquired cetuximab resistance and LDHB expression. We compared the expression levels of LDHB in the SW48R and C99R cell lines, which acquired resistance to cetuximab, and in the original cell lines. LDHB expression levels were significantly upregulated in the CRC cell lines that developed cetuximab resistance when compared to the original cell lines ( $\mathrm{P}<0.05$, Mann-Whitney U test) (Fig. 3). In addition, the data obtained using LC-MS/MS were consistent with data obtained by analysis using ELISA (data not shown).

\section{Discussion}

We showed that the expression level of LDHB may be a predictive biomarker for sensitivity to anti-EGFR mAbs by proteome analysis for the first time. Furthermore, our findings suggested that LDHB may also be involved in acquired resistance to anti-EGFR mAbs.

$\mathrm{LDH}$ is a key glycolytic enzyme catalyzing the conversion of pyruvate acid to lactic acid, and is composed of two major subunits, LDHA (muscle type, M subunit) and LDHB (heart type, $\mathrm{H}$ subunit). LDHA is reported to be involved in cell proliferation and metabolism in most cancers (31-34), while LDHB expression varies greatly among cancer types (35-40).
In 2012, LDHB expression was found to be correlated with cell growth in lung cancer with KRAS mutations (41), and its usefulness as a prognostic factor for triple-negative breast cancer, osteosarcoma and NSCLC was also reported by Li et al (35), McCleland et al (38), and Koh et al (42). Moreover, the effect of LDHB on the efficacy of some anticancer drugs has been investigated, and LDHB expression levels are reported to be correlated with the pathological complete response ratio, disease-free survival, and poor overall survival in patients treated with small molecule anticancer drugs, such as anthracycline and taxane $(11,43)$.

The activation of LDH has been reported to enhance the Warburg effect $(11,44,45)$. The Warburg effect causes the activation of intracellular stress signaling pathways by increasing glucose consumption and inducing hypoglycemia, and its activation is also known to lead to the development of resistance against anticancer drugs, such as 5-FU, carboplatin, and topoisomerase inhibitors (46-48). Furthermore, enhanced heat shock protein 90 activation, a molecular chaperone evoked during stress reactions, by the Warburg effect has also been reported to be involved in the development of resistance to anticancer drugs by activating client proteins, such as PI3K/Akt (49-51).

Unlike many previous studies of the effects of LDHB expression on prognosis or response to chemotherapy, which focused on LDHB alone, we demonstrated that the level of LDHB expression correlated with sensitivity to anti-EGFR $\mathrm{mAbs}$ by comprehensive analysis of proteins derived from CRC cell lines. Furthermore, LDHB expression levels were significantly upregulated with the acquisition of resistance to cetuximab in Cmab-S CRC cell lines. These results indicated that high LDHB expression was particularly important for the acquisition of drug resistance among many key factors involved in the development of drug resistance. In contrast, the LDHB expression level was low in the partially resistant HT55 cell line, and these data indicated that cetuximab sensitivity could not be evaluated with LDHB expression level alone. Although the cause of partial resistance to cetuximab in HT55 has not been clarified, various factors have been reported to 


$\begin{array}{rlllll}1 & \text { MATLKEKLIA } & \text { PVAEEEATVP } & \text { NNKITVVGVG } & \text { QVGMACAISI } & \text { LGKSLADELA } \\ 51 & \text { LVDVLEDKLK } & \text { GEMMDLQHGS } & \text { LFLQTPKIVA } & \text { DKDYSVTANS } & \text { KIVVVTAGVR } \\ 101 & \text { QQEGESRLNL } & \text { VQRNVNVFKF } & \underline{\text { IIPQIVKYSP }} & \text { DCIIVVSNP } & \text { VDILTYVTWK } \\ 151 & \text { LSGLPKHRVI } & \text { GSGCNLDSAR } & \text { FRYLMAEKLG } & \text { IHPSSCHGWI } & \text { LGEHGDSSVA } \\ 201 & \text { VWSGVNVAGV } & \text { SLQELNPEMG } & \text { TDNDSENWKE } & \text { VHKMVVESAY } & \text { EVIKLKGYTN } \\ 251 & \text { WAIGLSVADL } & \text { IESMLKNLSR } & \underline{\text { IHPVSTMVKG }} & \text { MYGIENEVFL } & \text { SLPCILNARG } \\ 301 & \underline{\text { LTSVINQKLK }} & \text { DDEVAQLKK } & \underline{\text { ADTLWDIQKD }} & \text { LKDL } & \end{array}$

\begin{tabular}{|c|c|c|c|c|c|c|c|c|}
\hline Start & - & End & Observed & $\mathrm{Mr}(\operatorname{expt})$ & $\mathrm{Mr}$ (calc) & Delta & Miss & Peptide \\
\hline 114 & - & 119 & 720.40 & 719.3927 & 719.3966 & -0.0039 & 0 & R.NVNVFK.F \\
\hline 120 & - & 127 & 957.62 & 956.6127 & 956.6059 & 0.0068 & 0 & K.FIIPQIVK.Y \\
\hline 173 & - & 178 & 754.38 & 753.3727 & 753.3731 & -0.0004 & 0 & R.YLMAEK.L \\
\hline 271 & - & 279 & 1011.57 & 1010.5627 & 1010.5583 & 0.0044 & 0 & R.IHPVSTMVK.G \\
\hline 300 & - & 308 & 959.56 & 958.5527 & 958.5447 & 0.0080 & 0 & R.GLTSVINQK.L \\
\hline 320 & - & 329 & 1176.60 & 1175.5927 & 1175.5822 & 0.0105 & 0 & K.SADTLWDIQK.D \\
\hline
\end{tabular}

Figure 1. Candidate fragment ions derived from LDHB by MS fit analysis. LDHB chain sequence and six candidate fragment ions (m/z 720.40, 957.62, 754.38, 1011.57, 959.56 and 1176.60) derived from LDHB determined by conducting MS fit analysis using LC-TOF MS. No trypsin digestion mistakes in the candidate ions were detected.
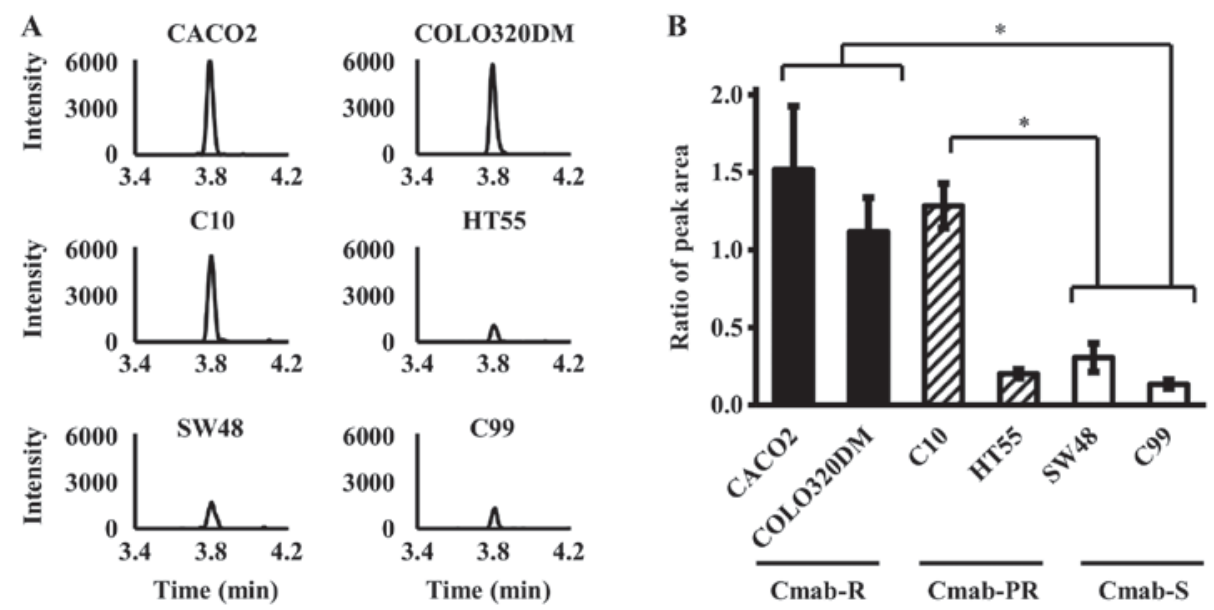

Figure 2. Expression levels of an LDHB-specific sequence using LC-MS/MS in cytoplasmic proteins derived from six CRC cell lines. (A) LC-MS/MS chromatogram of the LDHB-specific sequence (SADTLWDIQK) in six CRC cell lines. (B) Peak area ratios of the LDHB-specific sequence (SADTLWDIQK) and the internal standard in six CRC cell lines. Data are presented as the mean \pm standard deviation of triplicate experiments (One-way ANOVA, $\left.{ }^{*} \mathrm{P}<0.05\right)$.

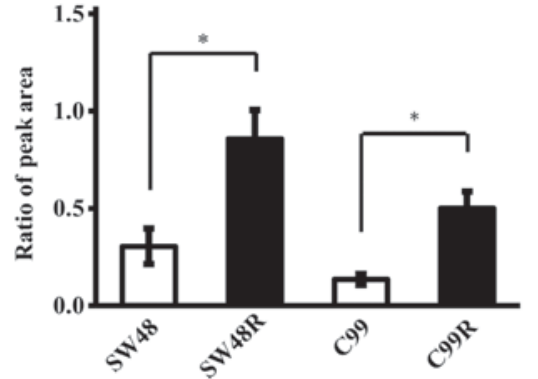

Figure 3. Changes in expression level of LDHB after acquisition of cetuximab resistance. Changes in LDHB expression levels in cytoplasmic proteins derived from cetuximab-sensitive cell lines (SW48 and C99) and cell lines that acquired cetuximab resistance (SW48R and C99R). Peak area ratios between the LDHB-specific sequence (SADTLWDIQK) and the internal standard in four CRC cell lines. Data are presented as the mean \pm standard deviation of triplicate experiments (Mann-Whitney $\mathrm{U}$ test, ${ }^{*} \mathrm{P}<0.05$ ).

be associated with resistance to cancer chemotherapy. Since primary resistance to drugs is known to be caused by so many factors, primary resistance to cetuximab in HT55 could be caused by many factors in addition to the increase of LDHB. Further detailed investigations are needed to examine drug resistance in this cell line.

One limitation of our study is that we could not clarify whether the drug resistance caused the increase in LDHB levels or whether increased levels of LDHB led to drug resistance. As mentioned above, LDHB is known to be an important factor related to the Warburg effect, and LDHB expression in tumor cells is reported to be increased to facilitate survival in hypoxic and low-energy conditions associated with insufficient angiogenesis. Since our results are based on an in vitro study, the survival environment of cancer cells is considered to be unchanged at least with respect to oxygen concentration and nutritional condition. In addition, LDHB protein level was low in the partially resistant HT55 cell line. According to these data, resistance to cetuximab was considered to be developed following changes associated with increased LDHB expression levels but LDHB protein level did not increase with the acquisition of resistance to cetuximab. The report by Sun et al (11) showed that LDHB deletion sensitized oral squamous cell carcinoma cell lines to taxane, whereas the introduction of LDHB 
decreased sensitivity to taxane. Furthermore, Lu et al (52) also reported that cetuximab showed antitumor efficacy due to downregulation of the $\alpha$ subunit of HIF-1 (HIF-1 $\alpha$ ). This in turn regulated the expression of LDHA and inhibition of glycolysis in cetuximab-sensitive head and neck squamous cell carcinoma cells in a HIF-1 $\alpha$ downregulation-dependent manner; these reports support our hypothesis. However, we could not prove our hypothesis with our data, and so a more detailed study of the role of LDHB in resistance to cetuximab is needed. In addition, because the mRNA-protein correlation with pyruvate metabolism in the Kyoto Encyclopedia of Genes and Genomes pathway, including LDHB, was reported to be low (1), we consider that development of an easy method to detect fluctuation in LDHB protein levels, other than analysis of mRNA, is needed for clinical application.

In conclusion, we found that LDHB may be an important factor affecting cetuximab sensitivity using comprehensive proteome analysis for the first time. We believe that these data could contribute to the improvement of chemotherapy for CRC patients and promote the development of a method to overcome resistance to anti-EGFR mAbs.

\section{Acknowledgements}

Not applicable.

\section{Funding}

This work was supported by JSPS KAKENHI (grant nos. JP16H00504 and JP15H00498).

\section{Availability of data and materials}

The datasets used during the present study are available from the corresponding author upon reasonable request.

\section{Authors' contributions}

KY, TA and DN conceived and designed the experiments. AN and MM performed the experiments. AN and TA analyzed the data and wrote the paper. KY, TA and DN revised the paper. All authors read and approved the final manuscript.

\section{Ethics approval and consent to participate}

Not applicable.

\section{Patient consent for publication}

Not applicable.

\section{Competing interests}

The authors declare that they have no competing interests.

\section{References}

1. Zhang B, Wang J, Wang X, Zhu J, Liu Q, Shi Z, Chambers MC, Zimmerman LJ, Shaddox KF, Kim S, et al: Proteogenomic characterization of human colon and rectal cancer. Nature 513 382-387, 2014
2. Li B, Li C, Guo M, Shang S, Li X, Xie P, Sun X, Yu J and Wang L: Predictive value of LDH kinetics in bevacizumab treatment and survival of patients with advanced NSCLC. Onco Targets Ther 11: 6287-6294, 2018.

3. Gregorc V, Novello S, Lazzari C, Barni S, Aieta M, Mencoboni M, Grossi F, De Pas T, de Marinis F, Bearz A, et al: Predictive value of a proteomic signature in patients with non-small-cell lung cancer treated with second-line erlotinib or chemotherapy (PROSE): A biomarker-stratified, randomised phase 3 trial. Lancet Oncol 15: 713-721, 2014.

4. Lazzari C, Spreafico A, Bachi A, RoderH,Floriani I, Garavaglia D, Cattaneo A, Grigorieva J, Viganò MG, Sorlini C, et al: Changes in plasma mass-spectral profile in course of treatment of non-small cell lung cancer patients with epidermal growth factor receptor tyrosine kinase inhibitors. J Thorac Oncol 7: 40-48, 2012.

5. Garrisi VM, Bongarzone I, Mangia A, Cremona M, De Bortoli M, Vaghi E, Galetta D, Pastorino U, Quaranta M, Abbate I and Paradiso A: Characterization of a serum protein pattern from NSCLC patients treated with Gefitinib. Clin Biochem 44: 936-940, 2011.

6. Pitteri SJ, Amon LM, Busald Buson T, Zhang Y, Johnson MM, Chin A, Kennedy J, Wong CH, Zhang Q, Wang H, et al: Detection of elevated plasma levels of epidermal growth factor receptor before breast cancer diagnosis among hormone therapy users. Cancer Res 70: 8598-8606, 2010.

7. Chung $\mathrm{CH}$, Seeley EH, Roder H, Grigorieva J, Tsypin M, Roder J, Burtness BA, Argiris A, Forastiere AA, Gilbert J, et al: Detection of tumor epidermal growth factor receptor pathway dependence by serum mass spectrometry in cancer patients. Cancer Epidemiol Biomarkers Prev 19: 358-365, 2010.

8. Taguchi F, Solomon B, Gregorc V, Roder H, Gray R, Kasahara K, Nishio M, Brahmer J, Spreafico A, Ludovini V, et al: Mass spectrometry to classify non-small-cell lung cancer patients for clinical outcome after treatment with epidermal growth factor receptor tyrosine kinase inhibitors: A multicohort cross-institutional study. J Natl Cancer Inst 99: 838-846, 2007.

9. Grossi F, Genova C, Rijavec E, Barletta G, Biello F, Dal Bello MG, Meyer K, Roder J, Roder H and Grigorieva J: Prognostic role of the VeriStrat test in first line patients with non-small cell lung cancer treated with platinum-based chemotherapy. Lung Cancer 117: 64-69, 2018.

10. Fidler MJ, Fhied CL, Roder J, Basu S, Sayidine S, Fughhi I, Pool M, Batus M, Bonomi P and Borgia JA: The serum-based VeriStrat $^{\circledR}$ test is associated with proinflammatory reactants and clinical outcome in non-small cell lung cancer patients. BMC Cancer 18: 310, 2018.

11. Sun W, Zhang X, Ding X, Li H, Geng M, Xie Z, Wu H and Huang M: Lactate dehydrogenase B is associated with the response to neoadjuvant chemotherapy in oral squamous cell carcinoma. PLoS One 10: e0125976, 2015.

12. Ferrer I, Quintanal-Villalonga Á, Molina-Pinelo S, Garcia-Heredia JM, Perez M, Suárez R, Ponce-Aix S, Paz-Ares L and Carnero A: MAP17 predicts sensitivity to platinum-based therapy, EGFR inhibitors and the proteasome inhibitor bortezomib in lung adenocarcinoma. J Exp Clin Cancer Res 37: 195, 2018.

13. Li J, Zhang B, Yang YF, Jin J and Liu YH: Aldehyde dehydrogenase 1 as a predictor of the neoadjuvant chemotherapy response in breast cancer: A meta-analysis. Medicine (Baltimore) 97: e12056, 2018

14. Yu KH, Levine DA, Zhang H, Chan DW, Zhang Z and Snyder M: Predicting ovarian cancer patients' clinical response to platinum-based chemotherapy by their tumor proteomic signatures. J Proteome Res 15: 2455-2465, 2016.

15. Chauvin A, Wang CS, Geha S, Garde-Granger P, Mathieu AA, Lacasse $\mathrm{V}$ and Boisvert FM: The response to neoadjuvant chemoradiotherapy with 5-fluorouracil in locally advanced rectal cancer patients: A predictive proteomic signature. Clin Proteomics 15: 16, 2018.

16. Fu J, Jiang H, Wu C, Jiang Y, Xiao L and Tian Y: Overcoming cetuximab resistance in Ewing's sarcoma by inhibiting lactate dehydrogenase-A. Mol Med Rep 14: 995-1001, 2016.

17. Sakurai T, Komeda Y, Nagai T, Kamata K, Minaga K, Yamao K, Takenaka M, Hagiwara S, Watanabe T, Nishida N, et al: Gankyrin contributes to tumorigenesis and chemoresistance in sporadic colorectal cancer. Digestion 4: 1-9, 2018.

18. Kawazoe A, Shitara K, Fukuoka S, Kuboki Y, Bando H, Okamoto W, Kojima T, Fuse N, Yamanaka T, Doi T, et al: A retrospective observational study of clinicopathological features of KRAS, NRAS, BRAF and PIK3CA mutations in Japanese patients with metastatic colorectal cancer. BMC Cancer 15: 258, 2015. 
19. Leto SM and Trusolino L: Primary and acquired resistance to EGFR-targeted therapies in colorectal cancer: Impact on future treatment strategies. J Mol Med (Berl) 92: 709-722, 2014.

20. Wong $R$ and Cunningham D: Using predictive biomarkers to select patients with advanced colorectal cancer for treatment with epidermal growth factor receptor antibodies. J Clin Oncol 26: 5668-5670, 2008.

21. Khambata-Ford S, Garrett CR, Meropol NJ, Basik M, Harbison CT, Wu S, Wong TW, Huang X, Takimoto $\mathrm{CH}$, Godwin AK, et al: Expression of epiregulin and amphiregulin and K-ras mutation status predict disease control in metastatic colorectal cancer patients treated with cetuximab. J Clin Oncol 25: 3230-3237, 2007.

22. Price T, Kim TW, Li J, Cascinu S, Ruff P, Suresh AS, Thomas A, Tjulandin S, Guan X and Peeters M: Final results and outcomes by prior bevacizumab exposure, skin toxicity, and hypomagnesaemia from ASPECCT: Randomized phase 3 non-inferiority study of panitumumab versus cetuximab in chemorefractory wild-type KRAS exon 2 metastatic colorectal cancer. Eur J Cancer 68: 51-59, 2016.

23. Molinari F, Felicioni L, Buscarino M, De Dosso S, Buttitta F, Malatesta S, Movilia A, Luoni M, Boldorini R, Alabiso O, et al: Increased detection sensitivity for KRAS mutations enhances the prediction of anti-EGFR monoclonal antibody resistance in metastatic colorectal cancer. Clin Cancer Res 17: 4901-4914, 2011.

24. Sartore-Bianchi A, Moroni M, Veronese S, Carnaghi C, Bajetta E, Luppi G, Sobrero A, Barone C, Cascinu S, Colucci G, et al: Epidermal growth factor receptor gene copy number and clinical outcome of metastatic colorectal cancer treated with panitumumab. J Clin Oncol 25: 3238-3245, 2007.

25. Cunningham D, Humblet Y, Siena S, Khayat D, Bleiberg H, Santoro A, Bets D, Mueser M, Harstrick A, Verslype C, et al: Cetuximab monotherapy and cetuximab plus irinotecan in irinotecan-refractory metastatic colorectal cancer. N Engl J Med 351: 337-345, 2004

26. Rankin A, Klempner SJ, Erlich R, Sun JX, Grothey A, Fakih M, George TJ Jr, Lee J, Ross JS, Stephens PJ, et al: Broad detection of alterations predicted to confer lack of benefit from EGFR antibodies or sensitivity to targeted therapy in advanced colorectal cancer. Oncologist 21: 1306-1314, 2016.

27. Pietrantonio F, Petrelli F, Coinu A, Di Bartolomeo M, Borgonovo K, Maggi C, Cabiddu M, Iacovelli R, Bossi I, Lonati $\mathrm{V}$, et al: Predictive role of BRAF mutations in patients with advanced colorectal cancer receiving cetuximab and panitumumab: A meta-analysis. Eur J Cancer 51: 587-594, 2015.

28. Rowland A, Dias MM, Wiese MD, Kichenadasse G, McKinnon RA, Karapetis CS and Sorich MJ: Meta-analysis of BRAF mutation as a predictive biomarker of benefit from anti-EGFR monoclonal antibody therapy for RAS wild-type metastatic colorectal cancer. Br J Cancer 112: 1888-1894, 2015.

29. Ashraf SQ, Nicholls AM, Wilding JL, Ntouroupi TG, Mortensen NJ and Bodmer WF: Direct and immune mediated antibody targeting of ERBB receptors in a colorectal cancer cell-line panel. Proc Natl Acad Sci USA 109: 21046-21051, 2012

30. Troiani T, Martinelli E, Napolitano S, Vitagliano D, Ciuffreda LP Costantino S, Morgillo F, Capasso A, Sforza V, Nappi A, et al: Increased TGF- $\alpha$ as a mechanism of acquired resistance to the anti-EGFR inhibitor cetuximab through EGFR-MET interaction and activation of MET signaling in colon cancer cells. Clin Cancer Res 19: 6751-6765, 2013.

31. Zhou X, Chen R, Xie W, Ni Y, Liu J and Huang G: Relationship between 18F-FDG accumulation and lactate dehydrogenase A expression in lung adenocarcinomas. J Nucl Med 55: 1766-1771, 2014.

32. Sheng SL, Liu JJ, Dai YH, Sun XG, Xiong XP and Huang G: Knockdown of lactate dehydrogenase A suppresses tumor growth and metastasis of human hepatocellular carcinoma. FEBS J 279: 3898-3910, 2012

33. Le A, Cooper CR, Gouw AM, Dinavahi R, Maitra A, Deck LM, Royer RE, Vander Jagt DL, Semenza GL and Dang CV: Inhibition of lactate dehydrogenase A induces oxidative stress and inhibits tumor progression. Proc Natl Acad Sci USA 107: 2037-2042, 2010.
34. Fantin VR, St-Pierre J and Leder P: Attenuation of LDH-A expression uncovers a link between glycolysis, mitochondrial physiology, and tumor maintenance. Cancer Cell 9: 425-434, 2006.

35. Li C, Chen Y, Bai P, Wang J, Liu Z, Wang T and Cai Q: LDHB may be a significant predictor of poor prognosis in osteosarcoma. Am J Transl Res 8: 4831-4843, 2016.

36. Chen R, Zhou X, Yu Z, Liu J and Huang G: Low expression of LDHB correlates with unfavorable survival in hepatocellular carcinoma: Strobe-compliant article. Medicine (Baltimore) 94: e1583, 2015.

37. Cui J, Quan M, Jiang W, Hu H, Jiao F, Li N, Jin Z, Wang L, Wang Y and Wang L: Suppressed expression of LDHB promotes pancreatic cancer progression via inducing glycolytic phenotype. Med Oncol 32: 143, 2015.

38. McCleland ML, Adler AS, Shang Y, Hunsaker T, Truong T, Peterson D, Torres E, Li L, Haley B, Stephan JP, et al: An integrated genomic screen identifies LDHB as an essential gene for triple-negative breast cancer. Cancer Res 72: 5812-5823, 2012.

39. Leiblich A, Cross SS, Catto JW, Phillips JT, Leung HY, Hamdy FC and Rehman I: Lactate dehydrogenase-B is silenced by promoter hypermethylation in human prostate cancer. Oncogene 25: 2953-2960, 2006.

40. Maekawa M, Taniguchi T, Ishikawa J, Sugimura H, Sugano K and Kanno T: Promoter hypermethylation in cancer silences LDHB, eliminating lactate dehydrogenase isoenzymes 1-4. Clin Chem 49: 1518-1520, 2003.

41. McCleland ML, Adler AS, Deming L, Cosino E, Lee L, Blackwood EM, Solon M, Tao J, Li L, Shames D, et al: Lactate dehydrogenase $\mathrm{B}$ is required for the growth of KRAS-dependent lung adenocarcinomas. Clin Cancer Res 19: 773-784, 2013.

42. Koh YW, Lee SJ and Park SY: Prognostic significance of lactate dehydrogenase B according to histologic type of non-small-cell lung cancer and its association with serum lactate dehydrogenase. Pathol Res Pract 213: 1134-1138, 2017.

43. Dennison JB, Molina JR, Mitra S, González-Angulo AM, Balko JM, Kuba MG, Sanders ME, Pinto JA, Gómez HL, Arteaga CL, et al: Lactate dehydrogenase B: A metabolic marker of response to neoadjuvant chemotherapy in breast cancer. Clin Cancer Res 19: 3703-3713, 2013

44. Hirschhaeuser F, Sattler UG and Mueller-Klieser W: Lactate: A metabolic key player in cancer. Cancer Res 71: 6921-6925, 2011.

45. Zhou M, Zhao Y, Ding Y, Liu H, Liu Z, Fodstad O, Riker AI, Kamarajugadda S, Lu J, Owen LB, et al: Warburg effect in chemosensitivity: Targeting lactate dehydrogenase-A re-sensitizes taxol-resistant cancer cells to taxol. Mol Cancer 9: 33, 2010.

46. Bhattacharya B, Mohd Omar MF and Soong R: The Warburg effect and drug resistance. Br J Pharmacol 173: 970-979, 2016.

47. Bhattacharya B, Low SH, Soh C, Kamal Mustapa N, Beloueche-Babari M, Koh KX, Loh J and Soong R: Increased drug resistance is associated with reduced glucose levels and an enhanced glycolysis phenotype. Br J Pharmacol 171: 3255-3267, 2014.

48. Hwang JH, Kim JY, Cha MR, Ryoo IJ, Choo SJ, Cho SM, Tsukumo Y, Tomida A, Shin-Ya K, Hwang YI, et al: Etoposide-resistant HT-29 human colon carcinoma cells during glucose deprivation are sensitive to piericidin A, a GRP78 down-regulator. J Cell Physiol 215: 243-250, 2008.

49. Jacobson C, Kopp N, Layer JV, Redd RA, Tschuri S, Haebe S, van Bodegom D, Bird L, Christie AL, Christodoulou A, et al: HSP90 inhibition overcomes ibrutinib resistance in mantle cell lymphoma. Blood 128: 2517-2526, 2016.

50. Flandrin P, Guyotat D, Duval A, Cornillon J, Tavernier E, Nadal N and Campos L: Significance of heat-shock protein (HSP) 90 expression in acute myeloid leukemia cells. Cell Stress Chaperones 13: 357-364, 2008.

51. Sain N, Krishnan B, Ormerod MG, De Rienzo A, Liu WM, Kaye SB, Workman P and Jackman AL: Potentiation of paclitaxel activity by the HSP90 inhibitor 17-allylamino-17-demethoxygeldanamycin in human ovarian carcinoma cell lines with high levels of activated AKT. Mol Cancer Ther 5: 1197-1208, 2006.

52. Lu H, Li X, Luo Z, Liu J and Fan Z: Cetuximab reverses the Warburg effect by inhibiting HIF-1-regulated LDH-A. Mol Cancer Ther 12: 2187-2199, 2013. 